Article

\title{
The Effect of Employee Proactive Personality and Felt Responsibility on Individual Corporate Social Responsibility Behaviors: The CSR Context Matters
}

Drew B. Mallory ${ }^{1}$, Deborah E. Rupp ${ }^{2, *}$, Niti Pandey ${ }^{3}$, Louis Tay ${ }^{4}$

1 Sasin School of Management, Sasa Pathasala, 254 Wang Mai, Pathum Wan District, Bangkok 10330, Thailand

2 Department of Psychology, George Mason University, 4400 University Drive, 3F5, Fairfax, VA 22030, USA

3 Department of Management and Marketing, Eastern Connecticut State University, 83 Windham St, Willimantic, CT 06226, USA

4 Department of Psychology, Purdue University, 703 Third Street, West Lafayette, IN 47907, USA

* Correspondence: Deborah E. Rupp, Email: drupp2@gmu.edu.

\begin{abstract}
This research explores the antecedents and consequences of felt responsibility for constructive change within the context of corporate social responsibility (CSR). A moderated mediation model is proposed wherein proactive personality predicts felt responsibility, which in turn influences three types of individual-level socially responsible behaviors both within and beyond organizational boundaries (i.e., socially responsible behaviors in the workplace, (refraining from) counterproductive work behaviors, and socially responsible behaviors outside the workplace). Perceptions of CSR were predicted to place a situational boundary condition on the effects of felt responsibility. Predictions tested on an employee sample showed that proactive personality drives socially responsible behaviors via felt responsibility, but that when individuals perceive a high level of CSR, the predictive power of felt responsibility is diminished (illustrating the potential power of socially responsible workplace environments). The findings suggest that internal CSR communication strategies may play an important role in encouraging prosocial behaviors of even those employees less predisposed to be socially responsible.
\end{abstract}

KEYWORDS: corporate social responsibility; CSR; micro-CSR; prosocial personality; felt responsibility; counterproductive work behaviors; citizenship behavior

\section{ABBREVIATIONS}

CSR, corporate social responsibility; CSRBs, corporate social responsibility behaviors; GSRBs, general social responsibility behaviors; CWBs, 
counterproductive work behaviors; OCB, organizational citizenship behavior

\section{INTRODUCTION}

It has become increasingly common for organizations to put forth effort aimed at eliciting positive social change through corporate social responsibility (CSR) initiatives, defined as discretionary firm activities designed to accomplish social and environmental outcomes alongside traditional economic aims [1,2]. Many such initiatives (e.g., those pertaining to philanthropy, recycling, and energy conservation) require employee engagement [3-6]. While scholars in strategic management, economics, and law have studied the antecedents and consequences of CSR at organizational and institutional levels of analysis, organizational scholars are now examining the "psychology of CSR" as it relates to employees [3,7]. Recognizing that individuals develop policies, enact programs, and carry out behaviors that cause either benefit or harm to stakeholders [8,9] leads us to question whether personality and other individual differences might play a role in employees' engagement in socially responsible behaviors [10].

To our knowledge, research has yet to study employees (as opposed to organizations) as stewards of socially responsible behaviors/actions (for exceptions, see $[8,11])$. That is, although there is a growing body of research focused on individuals' reactions to CSR [4,12], we see relatively little attention placed on the antecedents of employees' individual-level CSR behaviors. Drawing from research across psychology and management, we seek to address this issue by proposing that specific aspects of employee personality impacts whether employees will engage in socially responsible behaviors at work (and beyond). In doing so, we link the emerging findings on employee CSR perceptions with current knowledge regarding the psychological basis of socially responsible behaviors.

Our theoretical framework is presented in Figure 1. We first present a process by which employees' socially responsible behaviors are predicted distally by proactive personality [13] and proximally by individual differences in felt responsibility for constructive change [14,15]. Then, drawing on trait activation theory [16-18], we examine how employees' perceptions of their employer's CSR place a boundary condition on the extent to which these individual differences drive employee social responsibility. Consistent with past research, we depict felt responsibility as a context-specific "readiness" for proactive change-oriented behaviors [19] that is narrower in focus than the broader trait of proactive personality $[17,20]$. The focus on employee individual differences and the CSR context differentiates this study from those more focused on employee experiences of CSR. By placing specific individual differences as possible determinants of socially responsible behaviors, CSR perceptions are repositioned as cues for such CSR-consistent acts. This framing allows our research to depart from the convention of positioning CSR as a primary 
force acting upon employees and assumes a person-centric exploration of the socially responsible employee [21]. Furthermore, by measuring CSRconsistent behaviors in a way that corresponds to opportunities actually present in the workplace (versus intentions toward broad, generic supportive behaviors), we get closer to modeling the psychology of CSR.

In sum, we demonstrate that individual differences in proactive personality and felt responsibility are associated with employee CSR behaviors, as well as the refraining from counterproductive workplace behaviors. More importantly, we highlight the unique role that employee perceptions of their employer's CSR have on this effect. In the sections that follow, we briefly discuss why we believe an individual difference perspective is key to a complete understanding of CSR behavior; and provide more in-depth theoretical justification for the links in our model. Further, we highlight how understanding the basis of employees' social responsibility has significant practical implications for firms designing CSR initiatives aimed at fostering participation and engagement from their workforce.

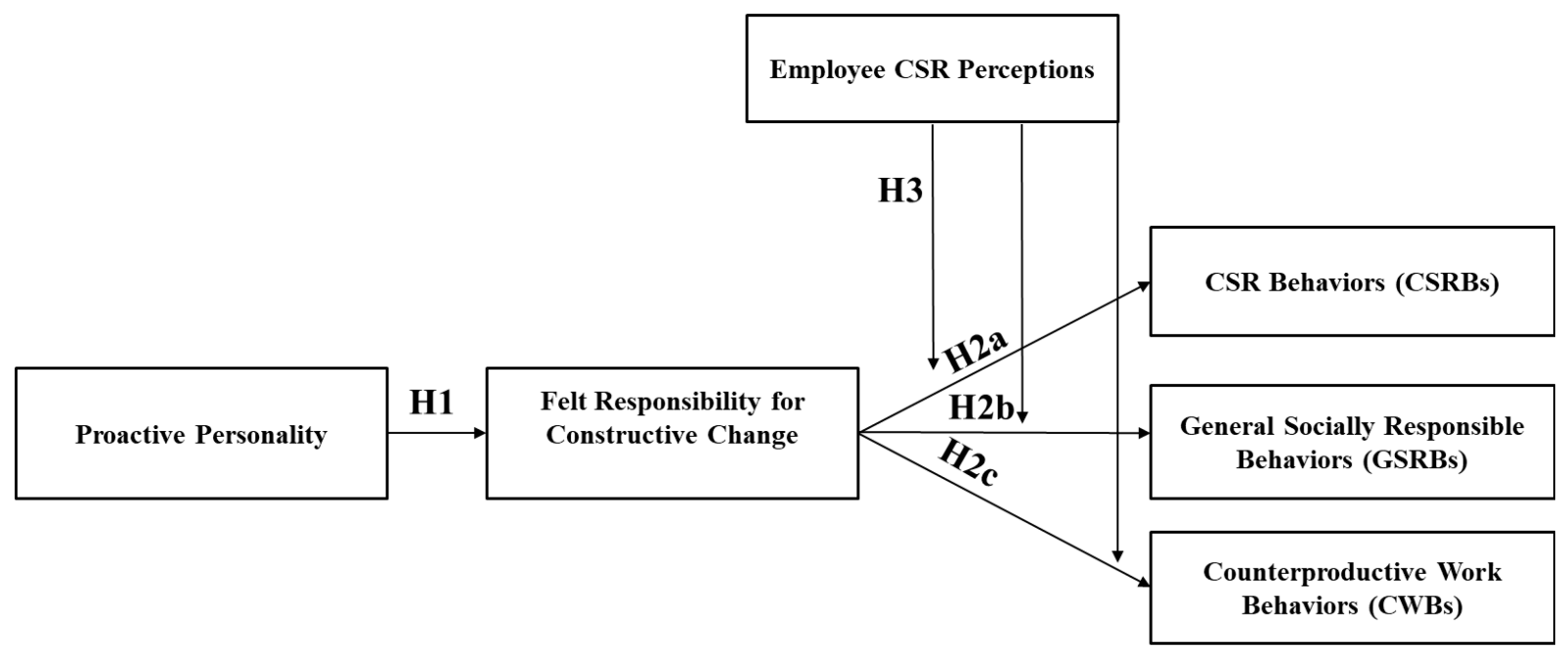

Figure 1. Theoretical model.

\section{PROACTIVE PERSONALITY AND FELT RESPONSIBILITY FOR CONSTRUCTIVE CHANGE}

Proactive individuals are described as being "relatively unconstrained by situational forces, and who effect environmental change... [and] take it upon themselves to have an impact on the world around them" [13]. Argued to be a component of personal initiative [22], proactivity is related to actively taking charge in the professional, personal, and social domains, including non-work prosocial activities (e.g., volunteerism; [23,19]). At work, proactive personality relates to discretionary behaviors, showing a relationship to not only organizational citizenship behaviors [24,25], but also to counterproductive behaviors [13,23,26-30].

That is, on the one hand, proactive individuals are more likely to take personal initiative on projects, innovate, and grow in their careers [25]. On 
the other hand, too much proactive behavior at work can be dysfunctional or counterproductive to organizational aims [13,27,28]. To unpack these tensions, researchers have called for increased focus on the situationspecific demonstrations of proactive tendencies [17].

Our theoretical model represents such a demonstration within an organizational CSR context. It connects prosocial personality to socially responsible behavior via individual differences in felt responsibility for constructive change, which is both a distinct outgrowth of more general responsibility research, and intertwined with the study of prosocial behavior [31]. Defined as "an individual's belief that he or she is personally obligated to bring about constructive change" even in the face of risk or no reward [15], this construct has emerged following decades of responsibility research, which has described feelings of responsibility arising from both state and dispositional characteristics. Initial research described a responsibility orientation, or a heightened sense of perceived responsibility for prosocial behaviors toward third parties arising from social reciprocity norms [32,33]. These early studies proposed that some individuals may be dispositionally more inclined to render aid to others. Later research sought to determine if and how responsible behavior could be situationally induced. The introduction of the bystander effect by Darley and Latané [34] highlighted the role that a contraindicating group may have on inhibiting individual impulses for responsible behavior. Likewise, Tilker [35] revealed that socially responsible behaviors could be inhibited or induced depending on how individuals internally ascribed responsibility for action in a given situation. Schwartz [36] bridged these two areas by showing that responsible behaviors can grow from a combination of personality and norms related to responsible behavior. Mayer, Duval, Holtz, and Bowman [37] showed that felt responsibility was the explanatory link between self-focus and helping behaviors, as moderated by the situational salience of a helping request.

Though feelings of responsibility had been studied in a work context before, e.g., Goranson and Berkowitz [38], Hackman and Oldham [39] brought the study of felt responsibility to the workplace by casting the construct in a new light-as the degree to which employees feel accountable for the results of their work. This employee-focused incarnation was markedly different from operationalizations in other responsibility research as it entirely omitted elements of social concern or obligation. The term "responsibility" here applied only to feelings of duty or obligation to complete tasks related to one's job, without extending to others in the organization (or beyond), or a more abstract sense of social or moral obligation. One of the three psychological states predicted in the job characteristics model as an antecedent of work motivation, experienced responsibility, was proposed as a mediator of the effects of work autonomy on beneficial work outcomes.

Much later, Morrison and Phelps [15] repositioned and re-broadened the study of felt responsibility at work by defining it in a way that reached 
beyond the ownership of prescribed duties. They theorized that employees high in responsibility beliefs would experience positive feelings when acting in a proactive/constructive way, while attaching negative valence to missed opportunities to do so. Combined, they predicted that these preferences would propel such employees to seek out varied opportunities to improve their environments. More similar to the helping literature than job characteristic theory's "experienced responsibility", the authors also positioned felt responsibility as an "attribute" or dispositional tendency related to individual initiative, as opposed to an induced state [40]. Empirically, the study linked felt responsibility to a beneficial proactive tendency toward taking charge and recommended that employers select for initially high levels of employee felt responsibility for constructive change, striving to develop the tendency thereafter. Fuller, Marler, and Hester [14] later made expansive theoretical additions to Morrison and Phelps' [15] definition of felt responsibility, expanded the construct's name (to felt responsibility for constructive change), and expanded its nomological network by reviving its prosocial nature. Differing from Morrison and Phelps [15] by arguing that the construct was best represented as a psychological state, Fuller et al. [14] empirically demonstrated links between trait proactivity, felt responsibility (acting as a state-like mediator), and several workplace change behaviors. Stating that "the proactive personality construct essentially reflects a 'readiness' to assume responsibility for constructive change”, their data confirmed that more proactive individuals were more likely to show felt responsibility at work, which subsequently affected the degree to which they achieved positive work outcomes (i.e., general proactive behaviors such as voice behavior and continuous improvement; p.1097).

In summary, felt responsibility research in the context of work has edged back toward the prosocial origins of the broader construct, with felt responsibility for constructive change portrayed as an attribute [15] that may be susceptible to environmental influence [14,31,39]. Capturing both trait- and state-like aspects, felt responsibility would, therefore, be construed as a mid-level individual difference variable, predicted by stable traits, yet functioning as a more proximal predictor of behavioral outcomes than traits alone [41]. We thus hypothesize a positive relationship between proactive personality and felt responsibility for constructive change.

Hypothesis 1: Proactive personality will be positively related to felt responsibility for constructive change.

\section{Felt Responsibility for Constructive Change and Responsible Behaviors}

Likewise, we hypothesize that felt responsibility for constructive change will predict responsible behaviors. Fuller and colleagues [14] significantly expanded the construct space for felt responsibility for 
constructive change by outlining the "other-oriented" nature of employees measuring high on this construct (p. 27). They strengthened Morrison and Phelps' [15] arguments that, in addition to behaviors directly advantageous for the organization, felt responsibility would lead to constructive workplace behaviors that target supra-organizational interests, such as those of external stakeholders. Despite these theoretical assertions, both Morrison and Phelps [15] and Fuller et al. [14] principally focused on how felt responsibility influences employees' desire to improve organizational efficiency and effectiveness. We contend this is an incomplete representation of a wider readiness for creating positive change that is both similar to and distinct from proactive tendencies alone [11,22]. To test this proposition, we consider three forms of socially responsible behaviors not previously studied in this context: Employee CSR behaviors, general socially responsible behaviors, and refraining from counterproductive work behaviors. We make a distinction between these variables in order to capture individual behaviors that would be associated with CSR as it is more traditionally defined, as well as behaviors beyond the bounds of CSR initiatives-both at work and beyond. We also do this to capture responsibility as manifested in both approach (e.g., help conserve energy) and avoid (e.g., refraining from participating in unethical acts) behaviors.

\section{Felt responsibility and CSRBS}

The current study proposes employee CSR behaviors (CSRBs) as a context-specific outcome of felt responsibility for constructive change. CSRBs are defined as discretionary, pro-social behaviors, aligned with the organization's CSR initiatives that employees may engage in while at work, and that benefit stakeholders beyond the organization, such as the community, society, or the ecological environment. Similar constructs have been explored within the environmental sustainability literature, such as employee pro-environmental behaviors and employee green behaviors, which are more narrowly tailored to the environment [9,42]. CSRB can also be contrasted with organizational citizenship behaviors (OCB) [24]. Despite similar terminology, OCB differs from the term corporate citizenship as it used in the macro CSR literature. Whereas corporate citizenship is quite aligned, and sometime used synonymously with CSR [43,44], OCB (which is typically couched within taxonomies of job performance) refers to discretionary behaviors employees may engage in as part of their work activities that ultimately increase organizational productivity and effectiveness (as opposed to benefiting stakeholders beyond shareholders [45,46]. Although research has shown felt responsibility to predict OCB [47,48], as argued above, we posit that individuals high in felt responsibility are also inclined toward prosocial behaviors that specifically align with existing CSR initiatives and that also benefit external stakeholders (see also Boiral's work, which has similarly 
discussed how the OCB construct might be extended to broader environmental issues [49]).

CSRBs are idiosyncratic to the organization to which the worker belongs, depend on access to behavioral opportunities, and are reflective of the organization's CSR initiatives. Thus, examples of CSRBs might range from specific acts such as recycling or energy conservation, longer-term activities like participation in corporate volunteering programs, or donating time or money to a firm-driven charitable initiative. Although CSRBs may relate to job requirements in some situations, previous research suggests the majority of CSRBs tend to be carried out by employees voluntarily and without a direct relationship to their formal job duties [9]. In contrast to OCBs, CSRBs are less likely to benefit the individuals performing them and their employing organization, as CSRBs focus on benefiting other stakeholder groups. Correspondingly, and in conjunction with the long history of research on felt responsibility across literatures, we expect that employees high in felt responsibility for constructive change will be more likely to not only be good citizens in general, but also, when afforded behavioral opportunities in the workplace, to engage in behaviors focused on contributing to some greater good extending beyond organizational success (i.e., CSRBs).

Hypothesis 2a: Employee felt responsibility for constructive change will be positively associated with CSRBs.

\section{Felt responsibility and GSRBS}

Consistent with past research [14,37] and with the depiction of felt responsibility for constructive change as a contextual demonstration of proactive personality, we also contend that individual differences in felt responsibility for constructive change will be predictive of socially responsible change-oriented behaviors outside of work. For the purposes of this study, such activities are referred to as general socially responsible behaviors (GSRBs). Like CSRBs, GSRBs pertain to behaviors that show a personal concern and active interest in creating constructive change for people not directly connected to one's inner group (i.e., colleagues or family). In contrast to CSRBs, however, GSRBs are constrained to actions initiated and carried out outside of the work domain (e.g., community volunteering, mentoring programs, or recycling at home), and are unassociated with one's employer and the CSR initiatives the employer may have underway.

In many ways, we expect GSRBs to be more self-originating than CSRBs, which offers us the chance to test the limits of the predictive power of felt responsibility for constructive change. That is to say, within organizations, CSRB opportunities may be physically and psychologically structured into the work setting, thereby increasing the ease with which workers may carry out CSRBs. The same may not be true outside the workplace, where experiences are not often so deliberately crafted or constrained. The 
looser structure of the non-work realm may translate to fewer behavioral opportunities or cues to engage in socially responsible behaviors [50]. That is to say, while there might technically be more varied opportunities to participate in community or environmental service activities outside of work-and although some of these activities may be embedded into formal systems (which act as cues; e.g., religious or community organizations), individuals must often seek out such opportunities entirely themselves. Further, participation in these discretionary activities may actually be hindered by unique constraints not present in the workplace. Family responsibilities, scheduling conflicts, or financial concerns, for example, may all impede individuals' abilities to engage in socially responsible behaviors outside of work. Thus, although we expect felt responsibility for constructive change to predict GSRBs, we expect the effect to be weaker compared to the felt responsibility-CSRB relationship.

Hypothesis 2b: Felt responsibility for constructive change will be positively associated to GSRBs.

\section{Refraining from CWBs}

Finally, we sought to include an outcome variable that represented the avoidance of or refraining from socially responsible behaviors, and thus also included counterproductive work behaviors (CWBs) in our model. CWBs refer to any intentional and unethical behaviors organizational members enact contrary to the organization's interests [51]. Little is known about the connection between felt responsibility and CWBs, though earlier scholars laid the groundwork to expect a negative relationship. For instance, responsibility researchers have argued that employees with high felt responsibility for constructive change are expected to feel strong ownership for the outcomes of their behaviors and a clear desire to affect their environment in a positive way [14,15]. Such employees are motivated, at least in part, by feelings of personal satisfaction and accomplishment produced through participation in change behaviors [20,40,52]. Furthermore, when employees feel a state of personal responsibility for change, they are actually more willing to correct their counterproductive behaviors [53]. This means that an orientation toward felt responsibility would likely inhibit participation in CWBs, most of which can rarely be construed as "constructive" and are most often overtly destructive. Certain forms of "positive deviance" [54], such as whistleblowing or prosocial rule breaking [55], may be acted out on behalf of external stakeholders, such as society, in order to bring about change within the organization. In this way, there are circumstances wherein proactive change behaviors that violate organizational desires may overlap with conventional measures of CWBs. However, by and large, CWBs seem to fall outside of this category, driven more by a mix of hostile and instrumental, rather than constructive, motives [56]. Indirect support for a negative relationship between felt responsibility for constructive change and CWBs is provided by Hoon and 
Tan [57] who found that those higher in felt responsibility for constructive change engaged in less social loafing in comparison to those lower in felt responsibility.

In one way, CWBs might be cast as a partial inverse of CSRBsemployee "irresponsible" acts. However, CWBs are clearly not a direct inverse of CSRBs-nor are they meant to be viewed as such. CSRBs are directed toward third-parties, and align with the organization's CSR efforts, while CWBs are usually aimed at or affect the company or its representatives (in a negative way). Further, CWBs include many behaviors that do not have CSRB analogues (e.g., internet surfing, gossiping), and vice versa. Consequently, we include CWBs in our investigation not as converse of CSRBs, but as a broader construct that can also represent, for employees high in felt responsibility, the refraining from (avoidance of) deviant behaviors (in contrast to approach-oriented CSRBs). Accordingly, we predict:

Hypothesis 2c: Felt responsibility for constructive change will be negatively related to CWBs.

\section{CSR Perceptions as a Boundary Condition}

According to trait activation theory [58], the expression of personality traits requires both the presence of traits and trait-relevant cues. Situations with particularly strong behavioral cues can mask detection of underlying traits by reducing behavioral variability [59]. That is, in socalled "strong" situations, behavioral demands on individuals tend to be clear and explicit, which has the tendency to reduce individual behavioral variation, as the majority of people will conform to established norms [18]. On the other hand, "weaker" situations create a sense of ambiguity, thus enabling more individual variation in behavior and consequently for traits to be more clearly revealed [58]. At its core, the concept of situational strength implies that the force of the situation may compel individuals to behave in certain ways that their individual differences may not otherwise predict. Using the trait of conscientiousness as an example, Meyer and colleagues illustrated the effect accordingly: "To the extent, then, that situational strength is increased in a manner that encourages conscientious behavior among those who are unlikely to do so when left to their own devices, this should reduce the criterion-oriented validity of trait conscientiousness" [60].

Previous research on proactivity suggests that such a situation-specific influence on certain proactive behaviors exists [17]. We expect that, when taken in conjunction with CSR perceptions, felt responsibility operates in a similar way. Within organizations perceived to be highly socially responsible, the power of individual differences in proactive personality and felt responsibility to predict prosocial (and antisocial) behaviors will be reduced. That is to say, we argue that our ability to predict CSRconsistent behaviors from felt responsibility will be determined by the 
extent to which employees perceive CSR-related cues from their organization. We expect that individuals perceiving high levels of CSR would demonstrate increased prosocial behaviors regardless of their individual differences [16]. This is because a firm perceived to be socially responsible likely has both opportunities in place to engage with CSR initiatives and strong norms for doing so [61]. In other words, as CSR perceptions grow stronger, individual differences in felt responsibility will predict CSR-relevant behaviors with decreasing strength. This is compared to when less CSR is perceived, wherein individuals will be more likely to express their dispositional tendencies [59,60,62]. Lower perceptions of CSR will thus present the strongest potential to observe the influence of felt responsibility for constructive change as an expression of individual differences in proactive responsibility on CSR-related behaviors [63].

Hypothesis 3: CSR perceptions will negatively moderate the effect of felt responsibility for constructive change on corporate social responsibility behaviors, such that the effect of felt responsibility for constructive change on CSRBs will increase as perceptions of CSR weaken.

Although not hypothesized, we also include in our model a moderation path from employee CSR perceptions on the relationship between felt responsibility and both GSRB and CWB. This again will allow for contrasts to more robustly test our theoretical position. Whereas we expect CSR perceptions to moderate felt responsibility's effect on CSRB, it may not moderate felt responsibility's effect on GSRB and CWB. That is, the situational norms created by CSR would be expected to more strongly constrain felt responsibility's effect on behaviors specific to CSR as compared to pro/antisocial behaviors in general.

\section{A Moderated Mediation Model of Felt Responsibility}

To test the extent to which proactive personality predicts felt responsibility for constructive change, and how felt responsibility for constructive change subsequently impacts CSRBs, GSRBs, and CWBs, moderated by CSR perceptions, we seek to test the moderated mediation model depicted in Figure 1. Based on situational strength arguments, we contend that within workplace settings, perceptions of CSR serve to constrain how individual differences in felt responsibility, as enabled by proactive personality, will manifest in "constructive change" behaviors. Addressing these constructs through a moderated mediation model is advantageous in that quantifying conditional direct and indirect effects in an integrated model makes it possible to numerically describe the observed effects from each variable simultaneously [64,65].

In addition to the extensions offered by our theoretical model, we also aim to make practical contributions through its testing. We not only hope to shed light on how individual difference variables such as proactive personality and felt responsibility for constructive change influence individual-level socially responsible behaviors, but also highlight how an 
organization's CSR might serve to inoculate against the risk of irresponsible behaviors by employees lower in felt responsibility.

\section{MATERIALS AND METHODS}

\section{Participants and Procedures}

In order to test our theoretical model, we required an organizational setting where employees had definitive exposure to CSR-related situational cues and corresponding pro-social behavioral opportunities [60], but that was large and complex enough that variance in CSR peceptions would be expected. Consequently, we identified a large work site that had a wide variety of CSR initiatives in place-a small public liberal arts university in the Northeastern United States. In addition to having implemented such initiatives, the organization also had a mechanism for informing employees of the programs, and had ensured a number of opportunities for engaging in socially responsible behaviors at work were available (which we cataloged for the creation of our CSRB measure [66]). CSR cues were present throughout the organizational environment, including printed instructions and visible promotion for lowering energy usage, comprehensive and accessible recycling programs (along with posted information, marked receptacles, and education), and a collection of campus- and community-based service activities. That being said, employees working at different parts of campus or in different roles were expected to have different levels of exposure to CSR information and formal communications (e.g., some workers in physical jobs may not work on a computer and therefore not receive email announcement about CSR initiatives). Together, this created the opportunity for variance both in employees CSR perceptions and opportunities to engage in socially responsible behaviors at work. A survey (paper and online) containing measures of all study variables along with a demographic questionnaire was distributed to full-time employees across several non-academic areas. Of the 450 employees solicited to participate, 135 completed the survey, resulting in a $30 \%$ response rate.

Participants ranged in age from 20 to 77 years of age $\left(x^{-}=43, S D=12.47\right)$ and were $49.3 \%$ female. Of the respondents who listed their ethnicity $(n=$ 124), $71 \%$ reported as being Caucasian, $14.5 \%$ as Hispanic, $6.4 \%$ as African American, and $8 \%$ as identifying with another ethnicity. On average, participants had worked for the organization for 8.29 years $(S D=6.36)$, with $74.8 \%$ reporting that they had no supervisory responsibilities.

\section{Measures}

Participants were asked to respond to all items on a five-point Likerttype scale (e.g., 1 = strongly disagree and 5 = strongly agree). Proactive personality $(\alpha=0.87)$ was measured using the 17-item Proactive Personality Scale [13], while felt responsibility for constructive change ( $\alpha=$ 0.78 ) was measured using the five-item scale developed by Morrison and 
Phelps [15]. Sample items include "I excel at identifying opportunities" and "I feel a personal sense of responsibility to bring about change at work", respectively. Employee perceptions of CSR $(\alpha=0.89)$ was measured using Jones et al.'s [66] 8-item scale of perceived corporate social performance. Item wording was minimally modified to reflect the culture of the organization surveyed in this study (e.g., "this company" became "my organization"). The measure included items such as, "My organization takes part in voluntary or charitable activities," and "My organization is active in helping its community."

CSR behaviors (CSRBs) were measured using ten items developed for this study ( $\alpha=0.80$ ), to reflect CSR-consistent behaviors employees could actually enact at work. Items were drawn from a catalog of socially responsible behavioral opportunities collected from the organization. Subject matter experts well-versed in the literature on employee CSR participation reviewed the items to ensure their fit with formal definitions of CSR, including research on employees' contributions to environmental sustainability (i.e., "green behaviors"; [9]). Items reflecting ten distinct CSR behaviors were retained. From this set of items, we created 11 analogous items for our companion general socially responsible behaviors (GSRB) measure $(\alpha=0.86)$. Each set of items was first tested on a pilot sample to ensure internal consistency reliability. Examples of CSRB items include: "I recycle at the office," "I participate in volunteer programs at work," and "I donate money when my organization is raising funds for charity or disasters". Examples of GSRBs items include: "I recycle at home," and "I shut off the lights when I leave the room" (The complete CSRB and GSRB scales are available from the authors upon request).

Counterproductive work behavior was assessed using the 17-item scale ( $\alpha=0.90)$ developed by Skarlicki and Folger [67]. Sample items include, "I tried to look busy while wasting time", and "I spent time on personal matters while at work".

\section{Tests of measurement model and descriptive statistics}

Confirmatory factor analyses (CFA) were carried out to examine the relationships between the constructs of interest and their distinctions from each other. Each latent construct was represented using item-parcels, which can assist in increasing the ratio of sample size to estimated parameters in the structural models and is appropriate when items are both congeneric and unidimensional $[68,69]$. All construct indicators were allocated to a single item parcel, with each parcel constructed from the average of its randomly assigned indicators. In this process, we also produced a series of alternate models, each comprised by collapsing one or more constructs within the model. As recommended, multiple fit indices were estimated [70], which are reported in Table 1. Model comparisons showed that the proposed model showed satisfactory fit to the data. The proposed model also demonstrated superior fit over alternative models. 
Table 1. Goodness-of-fit indicators of Single-factor Models for Study Variables $(n=94)$.

\begin{tabular}{lccccc}
\hline Construct & $\chi^{2}$ & $d f$ & CFI & RMSEA & SRMR \\
\hline 1-factor model & $874.13^{*}$ & 189 & 0.43 & 0.20 & 0.17 \\
4-factor model & $486.51 *$ & 183 & 0.74 & 0.13 & 0.13 \\
5-factor model $a$ & $481.81 *$ & 179 & 0.75 & 0.14 & 0.12 \\
5-factor model $b$ & $273.44^{*}$ & 179 & 0.92 & 0.08 & 0.09 \\
6-factor model & $265.72 *$ & 174 & 0.92 & 0.08 & 0.09 \\
\hline
\end{tabular}

Notes. $N=94$; CFI = confirmatory fit index $(>0.90=$ good $)$; RMSEA = root mean square error of approximation $(<0.08=$ good, $<0.10=$ acceptable); SRMR = standardized root mean square residual ( $<0.08$ = acceptable); 4 -factor model combines CSR Behaviors with general socially responsible behaviors and CSR perceptions; 5-factor model $a$ combines CSR Behaviors with CSR perceptions; 5-factor model $b$ combines CSR Behaviors with general socially responsible behaviors; * $p<0.001$.

Table 2. Descriptive statistics, internal consistency reliabilities, and intercorrelations among study variables.

\begin{tabular}{lcccccccc}
\hline Variable & $\boldsymbol{M}$ & $\boldsymbol{S D}$ & $\mathbf{1}$ & $\mathbf{2}$ & $\mathbf{3}$ & $\mathbf{4}$ & $\mathbf{5}$ & $\mathbf{6}$ \\
\hline 1. Proactive Personality & 3.83 & 0.49 & $(0.87)$ & & & & & \\
2. Felt Responsibility & 3.88 & 0.64 & $0.52^{* *}$ & $(0.78)$ & & & & \\
3. CSR Perceptions & 4.0 & 0.61 & 0.11 & $0.26^{*}$ & $(0.89)$ & & & \\
4. CSR Behaviors & 3.63 & 0.67 & $0.31^{*}$ & $0.30^{* *}$ & $0.27^{*}$ & $(0.80)$ & & \\
5. General Socially Responsible Behaviors & 3.80 & 0.66 & $0.27^{*}$ & $0.37^{* *}$ & $0.38^{* *}$ & $0.799^{* *}$ & $(0.86)$ & \\
6. Counterproductive Work Behaviors & 1.84 & 0.62 & -0.11 & $-0.40^{* *}$ & $-0.29^{* *}$ & $-0.41^{* *}$ & $-0.43^{* *}$ & $(0.84)$ \\
\hline
\end{tabular}

Note. $N=94 ;{ }^{*} p<0.01,{ }^{* *} p<0.001$; Internal-consistency reliability estimates (coefficient alphas) are reported in the parentheses along the diagonal.

Next, we examined the bivariate correlations between the variables in the study, as shown in Table 2. Table 2 also reports the means, standard deviations, and internal consistency reliabilities (coefficient alphas) for all study variables. Scores on all measures indicated an acceptable level of reliability [71]. The majority of the constructs significantly correlated with one another and mirrored our expected relationships. It is noteworthy that proactive personality did not relate to CSR perceptions, whereas felt responsibility did. This strengthens our argument that felt responsibility is a more contextualized indicator of the overarching proactive tendency. As CSRBs and GSRBs showed a particularly strong correlation with each other $(0.79, p<0.001)$, we checked the data for multicollinearity. To do so, we assessed the variance inflation factor (VIF) values for each of our constructs, and found them all to be lower than 3.5-significantly under the 10.0 threshold [72]. Nevertheless, to minimize multicollinearity concerns, we mean-centered all variables in all subsequent analyses [73].

\section{RESULTS}

The full moderated mediation model was tested for each outcome variable (CSRBs, GSRBs, and CWBs) using Hayes' [64] PROCESS macro (Model 14) for SPSS (v. 22), which applies conditional path analysis to simultaneously assess all the hypotheses collectively. Following the recommendations of Edwards and Lambert [74], we obtained bias- 
corrected bootstrapped confidence intervals for the conditional indirect effects (using 5000 bootstrap samples). Participants with missing values for variables of any analyses were automatically excluded from all analyses by PROCESS, which reduced the sample size to 94 . Analyses were all two-tailed with alpha set at 0.05 .

As shown in Table 3, Hypothesis 1, predicting that proactive personality would positively relate to felt responsibility for constructive change, was supported, as evidenced by the significant main effect of proactive personality on CSRBs. Hypothesis 2a, which predicted a relationship between felt responsibility for constructive change and CSRBs, was not supported, in that a significant main effect was not detected for felt responsibility in predicting CSRB, although this main effect was qualified by a significant felt responsibility $\times$ CSR perceptions interaction, which we discuss below. Consistent with Hypotheses $2 \mathrm{~b}$ and 2c, a significant main effect of felt responsibility for constructive change on both GSRB and CWBs was found.

Table 3. Regression results.

\begin{tabular}{|c|c|c|c|c|c|c|c|c|}
\hline \multirow[t]{2}{*}{ Predictor } & \multicolumn{2}{|c|}{$\begin{array}{c}\text { Felt } \\
\text { Responsibility }\end{array}$} & \multicolumn{2}{|c|}{ CSR Behaviors } & \multicolumn{2}{|c|}{$\begin{array}{c}\text { General Socially } \\
\text { Responsible } \\
\text { Behaviors } \\
\end{array}$} & \multicolumn{2}{|c|}{$\begin{array}{c}\text { Counterproductive Work } \\
\text { Behaviors }\end{array}$} \\
\hline & $\boldsymbol{B}$ & $S E$ & $\boldsymbol{b}$ & $S E$ & $\boldsymbol{b}$ & $S E$ & $b$ & $S E$ \\
\hline Proactive Personality & $0.64 * *$ & 0.12 & $0.31 *$ & 0.14 & 0.15 & 0.14 & 0.16 & 0.14 \\
\hline Felt Responsibility & & & 0.15 & 0.11 & $0.23 *$ & 0.11 & $-0.42 * *$ & 0.11 \\
\hline CSR Perceptions & & & 0.15 & 0.10 & $0.30 * *$ & 0.11 & -0.15 & 0.10 \\
\hline Interaction term & & & $-0.57 * *$ & 0.17 & -0.31 & 0.17 & 0.39 & 0.16 \\
\hline$R^{2}$ (Adjusted) & \multicolumn{2}{|c|}{$0.24^{* *}\left(0.21^{* *}\right)$} & \multicolumn{2}{|c|}{$0.26^{* *}(0.23 * *)$} & \multicolumn{2}{|c|}{$0.25^{* *}(0.22 * *)$} & \multicolumn{2}{|c|}{$0.25^{* *}(0.22 * *)$} \\
\hline
\end{tabular}

Note. $N=94 ;{ }^{*} p<0.05,{ }^{* *} p<0.01$.

The hypothesized model proposed second stage moderated mediation (PROCESS model 14; [64]) wherein felt responsibility mediated the effect of proactive personality on CSRBs, GSRBs, and CWBS with CSR perceptions moderating the paths between felt responsibility and its associated outcomes. This meant that the proposed effects of proactive personality (if any) on the three outcome variables were expected to be conditional upon the interaction between felt responsibility and CSR perceptions, with felt responsibility's effect constrained by the strength of CSR perceptions.

Table 4 presents the corresponding estimates and bias-corrected bootstrapped $95 \%$ confidence intervals for the conditional indirect effects of proactive personality, via felt responsibility for constructive change, on the three outcomes studied. As indicated by the non-overlapping confidence intervals in the index of moderated mediation for both CSRBs and CWBs, and the overlapping confidence intervals for GSRBs, CSR perceptions were found to moderate the effect of felt responsibility on CSRB and CWBs, but not GSRBs. This confirms Hypothesis 3, as well as our expectation that CSR perceptions would be more relevant for creating a 
strong situation (i.e., constrain the effect of individual differences) around workplace (as opposed to nonworkplace) behaviors.

Table 4. Estimates and bias-corrected bootstrapped 95\% confidence intervals for the conditional indirect effect of proactive personality on employee behaviors at \pm 1 standard deviation of CSR perceptions.

\begin{tabular}{c|c|c|c|c|c|c}
\hline \multirow{2}{*}{$\begin{array}{c}\text { Level of CSR } \\
\text { Perceptions }\end{array}$} & \multicolumn{3}{|c|}{ CSR Behaviors } & \multicolumn{2}{c|}{$\begin{array}{c}\text { General Socially Responsible } \\
\text { Behaviors }\end{array}$} & \multicolumn{2}{c}{$\begin{array}{c}\text { Counterproductive Work } \\
\text { Behaviors }\end{array}$} \\
\cline { 2 - 7 } & Estimate $(S E)^{\dagger}$ & $C I$ & Estimate $(S E)^{\dagger}$ & $C I$ & ${\text { Estimate }(S E)^{\dagger}}^{C I}$ \\
\hline-1 SD & $0.32(0.13)$ & {$[0.12,0.63]$} & $0.27(0.12)$ & {$[0.08,0.56]$} & $-0.42(0.12)$ & {$[-0.70,-0.22]$} \\
\hline+1 SD & $-0.13(0.13)$ & {$[-0.44,0.09]$} & $0.02(0.14)$ & {$[-0.28,0.28]$} & $-0.11(0.10)$ & {$[-0.33,0.08]$} \\
\hline
\end{tabular}

Note. $N=94 ; \mathrm{CI}=$ confidence interval; ${ }^{\dagger}$ Bootstrapped estimates for the standard error (SE) are presented.

Figure 2 illustrates the simple main effects of felt responsibility on CSRBs and CWBs at \pm 1 standard deviation of CSR. In support of Hypothesis 3 , felt responsibility for constructive change significantly and positively predicted CSRBs for employees with lower CSR perceptions $(b=0.32, S E=$ $0.13, p<0.00)$, but not for those reporting higher CSR perceptions $(b=-0.13$, $S E=0.13, n s)$. Similarly, felt responsibility showed a negative relationship with CWBs for employees who perceived low CSR $(b=-0.42, S E=0.12, p<$ 0.00 ), while no such relationship was identified for those with high CSR perceptions $(b=-0.11, S E=0.10, n s)$. Together, these findings support the prediction that those with higher felt responsibility would report finding ways to carry out more prosocial behaviors and fewer counterproductive acts even when situational cues are weak, while employees with the strongest CSR perceptions tended to act homogenously in their prosocial acts regardless of their levels of felt responsibility.
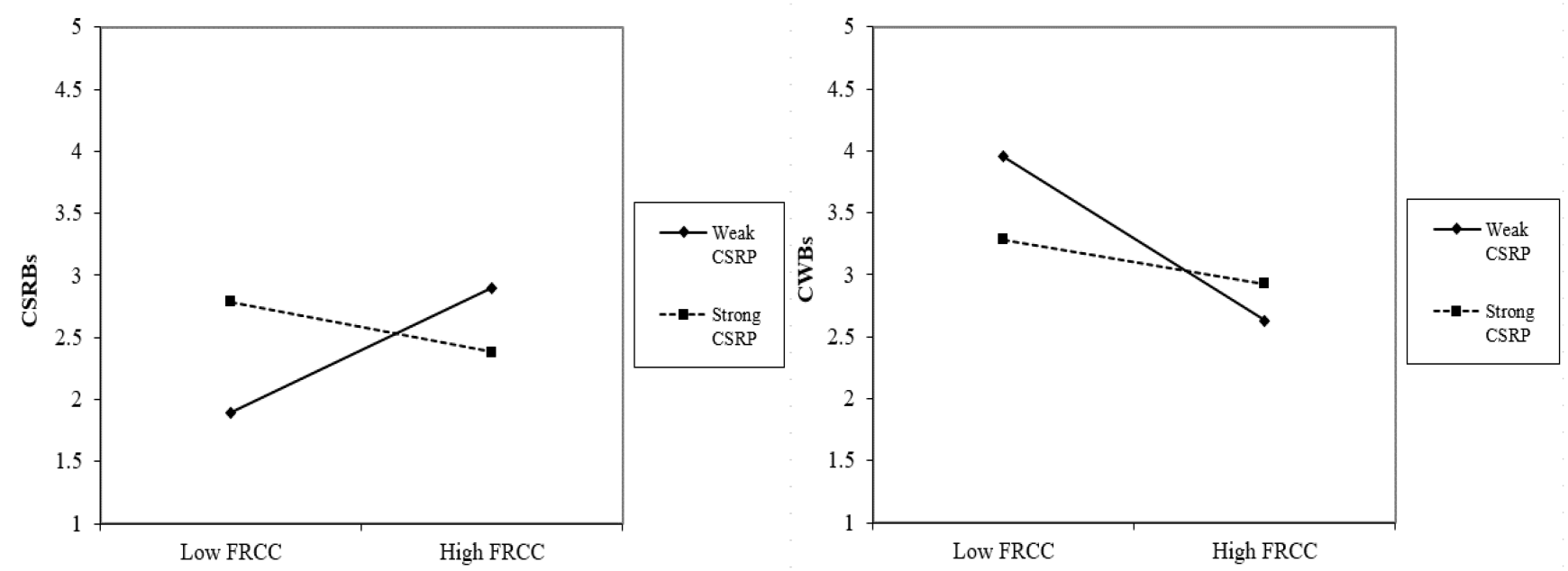

Figure 2. Moderation results. Note. $\mathrm{CSRBs}=$ corporate social responsibility behaviors; $\mathrm{CSRP}=\mathrm{CSR}$ perceptions; FRCC = felt responsibility for constructive change. The x-axis represents felt responsibility for constructive change at one standard deviation (SD) above and below the mean. 


\section{DISCUSSION}

Although employee-focused CSR research continues to expand, little is known about how individual differences influence individual CSR behaviors [3]. Our study makes a distinct contribution to the field by proposing and demonstrating the effect of specific dispositional and situational characteristics on employee behaviors in the CSR context. Our data suggest that felt responsibility for constructive change mediates the effect of proactive personality on CSRBs, but consistent with the notion of situational strength $[18,58]$, is contingent on employees' CSR perceptions, with the most pronounced effect of felt responsibility on CSRB when CSR perceptions are low (reflecting fewer perceived CSR norms; [16]). When employees perceived the organization as engaging more strongly in CSR, the moderated mediated effect was attenuated. Our results show the relevance of examining individual differences, as well as the situational context, when considering the extent to which employees will choose to engage in CSR behaviors. Such findings are crucial for the development of organizational practices aimed at fostering employee engagement in CSR.

The inclusion of GSRBs and CWBs in our model also allowed us to contrast the felt responsibility $\times$ CSR perception interaction effect on CSR behaviors with its effect, both on more general socially responsible behaviors outside of work, as well the refraining from counterproductive behaviors at work. Interestingly, although felt responsibility predicted both GSRBs and (the withholding of) CWBs, employee CSR perceptions were only found to moderate the effect of felt responsibility on behaviors enacted at work (CSRBs and CWBs). We originally expected to only find a moderation effect on CSRBs, given the CSR context was expected to mostly create norms around behaviors linked to specific CSR initiatives. However, it seems that CSR creates a more general ethical context that can also create norms around refraining from more general counterproductive behaviors. That being said, this effect did not appear to generalize beyond the workplace, evidenced by the lack of moderation effect for GSRB. Future research is needed to tease apart if this lack of moderation effect was due to a true lack of transfer, or the presence of stronger, counteractive norms in the non-work context.

\section{Contribution to Theory}

This research integrates the CSR and personality/responsibility literatures, positioning CSR as a topic well-suited for study within the broader responsibility literature. Building on prior scholarship on felt responsibility for constructive change and strengthening claims behind proactive personality (an important antecedent of felt responsibility; [14]), the moderated mediation effects found for CSRBs and CWBs supports the contention that felt responsibility for constructive change is narrower in scope than proactive personality, in that the former seems to better capture proactive change-oriented behaviors in the workplace, while 
necessarily preceded by the latter [13]. To our knowledge, this is the first study that tests either construct in this way within an actual workplace setting. These findings also show that felt responsibility can predict responsible behaviors directed toward third parties outside of the company and repress CWBs-something that has previously only been suggested for proactive personality.

This research also departs from past research in how the impact of CSR on employees was assessed. Whereas most of the micro CSR research to date has suggested that CSR directly influences employee attitudes and behaviors [7], the current study adopted a person-centric approach to CSR [75]. Employees' personal attributes interacted with CSR cues present in the environment to influence employees' own responsible behavior (or lack thereof). The results reported suggest that felt responsibility for constructive change may be an important indicator of responsible behaviors, especially when the organizational environment lacks strong cues to be socially responsible. This study is also the first of its kind to demonstrate that CSR perceptions (consistent with the concept of situational strength, [58]), can strengthen or weaken the extent to which individual differences influence responsible behaviors at work. Perceptions of the organization's efforts to engage in CSR seem to have an important impact on employees' socially responsible behaviors-even for those less predisposed to act in proactively socially responsible ways [16].

\section{Practical Implications}

As individuals are ultimately responsible for acts of social and environmental responsibility (but not all individuals are equally predisposed to engage in consistent prosocial behaviors), the findings from this study have implications for the importance of CSR communication, as well as selection, promotion, and training within organizations. Our data suggest that perceptions that a company strongly endorses and participates in CSR can overcome the effects of individual differences on responsible actions at work. This underscores the importance of communication and feedback of CSR activities to employees [7]. Of course, this may not be a straightforward task. The host organization in this study had existing CSR initiatives, with corresponding communication strategies, in place. Despite this, employee CSR perceptions varied. This is not unexpected. Previous research has revealed that many employees are often unaware, or even mistrusting, of CSR initiatives, even when they are communicated broadly [76]. Future research might explore what factors influence employee attention to and retention of CSR communication, such as preference for CSR in general, the specific type of CSR perceived, or other personality factors influencing the acceptance of and participation in CSR initiatives [10]. Beyond this, structural factors like work location, supervisor, hierarchical status, or hours worked could be measured as predictors of CSR awareness. Similarly, differences in individual values, justice experiences, and 
perceptions of CSR authenticity have been shown to affect how individuals process information relevant to CSR [77-79]. Regardless, organizations should expect that, despite actual practices in place, variance in employees' awareness of CSR initiatives will exist, and plan communication strategies accordingly.

Further, employees with the highest levels of felt responsibility were observed to withhold CWBs when CSR perceptions were low, but were not distinguishable from those with less felt responsibility in the presence of strong CSR perceptions. In other words, a prosocial "norming” influence of CSR was manifest even for employees with low levels of felt responsibility-if they had strong CSR perceptions. Estimates indicate that every year the US corporate sector loses roughly \$6-200 billion due to a range of deviant behaviors at work [80]. Targets of CWBs also experience negative effects on physical health and wellbeing [81], and even those who carry out CWBs may experience stress-related health risks [82]. Our findings therefore reveal additional benefits to employees and employers reaped via CSR.

Lastly, our results suggest that for organizations that have not yet established a strong CSR climate (creating norms for socially responsible behavior throughout the organization), there may be a benefit to selecting employees with high levels of felt responsibility for constructive change. In contrast, a strong CSR climate may compensate for situations where an organization's workforce might vary in felt responsibility. Armed with this knowledge, organizations can strive to capitalize on the effects borne of strong CSR perceptions through reducing the perceptual variance across employees in such a way that employees more consistently experience the organization as being strongly socially responsible.

\section{Limitations}

Our findings should be considered against the study's limitations. A key limitation of this study is that the data were self-reported and collected simultaneously, which can introduce several forms of common method bias (CMB). That being said, we felt self-report strategies were appropriate in this case [83]. That is, many of the key constructs in this study were perceptual (i.e., felt responsibility for constructive change, CSR perceptions, etc.) and therefore unlikely to be known by others (cf. [84]). In using self-report measures for participant prosocial behaviors (i.e., CSRBs and GSRBs), we adopted arguments made by others $[79,85,86]$, who have reasoned that using self-report measure for certain prosocial behaviors may be preferable over third-party observations when the focal research question pertains to respondent motivations and intentions behind the target behaviors. Nonetheless, future research might consider using objective reports, such as hours volunteered or dollars donated, as a balance to self-reported behaviors. Further, as suggested by Spector [87], we took a number of steps to reduce the risk of CMB contaminating our results. For example, we separated measures on the survey addressing 
similar constructs from one another (e.g., proactive personality and felt responsibility for constructive change), and followed the recommendations of Chung and Monroe [88] in instructing participants that no personal information would be shared with the university or their supervisor. Respondents were also not personally identified on any research materials.

In addition, our application of trait activation theory assumed that participants were both subject to trait-related behavioral cues (CSRrelated information) and opportunities for CSRBs, and that individual CSR perceptions, acting as a proxy for situational strength, would influence the degree to which individual differences would predict engagement in these behaviors. As far as we are aware, this is the first time CSR perceptions have been positioned in this way. As we have described, we took pains to explicitly determine the trait-activation potential for CSRBs across the organization prior to administering the survey through interviews with organizational representatives and consultation with subject matter experts. However, the objective situational strength for each individual surveyed was, of course, not possible to determine, nor was it our focus. Broad job-based situational strength measures [60] expansively survey individuals across many aspects of a job, and are designed to capture the strength of the entire work experience, but contain many items that may be irrelevant to a more narrowly-defined psychological experience. Adapting such a measure for a CSR context seemed unlikely to capture the day-to-day CSR experience of employees, who may not have had information on company CSR practices or policies beyond a general knowledge. We used a traditional measure of CSR perceptions because, in conjunction with the objectively verified behavioral opportunities provided by the organization, it allowed us to capture only the perceptions of normative organizational practices of CSR. Nevertheless, we acknowledge that the measure we adopted was not designed with this theoretical purpose in mind, and thus may not act as the ideal proxy for assessing CSR-related situational strength. In the future, comparing measures of CSR perceptions to existing or modified situational strength measures would shed light on this issue.

Also, our sample size was limited and our study was carried out in a single organization. It could be argued that a multi-organizational sample is necessary to tap variance in CSR perceptions, and given our focal organization had formal CSR initiatives in place, perhaps we missed the "low" end of this construct (i.e., faced restricted range on this variable). However, our focal organization was large, and we sampled across jobs and job contexts. Unfortunately our data did not allow us to test for nonindependence of observations (i.e., we were not able to detect if employees were nested within supervisors), and our small sample size precluded us from carrying out any multi-level analyses. All that being said, our data showed not only adequate statistical power to detect effects, but the CSR perceptions variable also showed as much variance as the other variables in our model. If anything, the estimates we report are conservative in 
nature, and we would expect larger effect sizes with larger samples taken from a variety of organizations. Nonetheless, future work should consider replicating our results in a larger, multi-organizational sample or, at the least, within a for-profit organization outside of higher education.

Finally, the CWB measure we employed was originally developed within the context of retaliation research. We recommend that future work replicate our findings incorporating other measures more commonly used to assess CWB (e.g., [89]). Relatedly, as mentioned earlier, the CSRB and GSRB measures were developed specifically for the population sampled. This uniquely afforded us CSR-consistent behavioral lists ensured to be relevant for the study context and participants sampled. As these measures have not been afforded the benefit of vetting by past research, future research is needed to provide further validity evidence for the approach we have taken. A full taxonomy of CSRBs, developed much in the way that Dilchert and Ones [42] and Ones and Dilchert [9] have done for employee green behaviors, may be required to more fully understand the unfolding of the process we hypothesize, across samples (and organizations).

\section{CONCLUSION}

This study offers insight into the proactively responsible individual while on and off the job. It clarifies the antecedent role and nature of proactive personality on felt responsibility for constructive change and expands the theoretical space for each. Furthermore, it introduces the contextual significance of CSR perceptions in understanding the relationship between felt responsibility and two work-related behavioral domains (CSRBs and CWBs), as well as a set of prosocial behaviors outside of work (GSRBs). The highly responsible individual behaves in the predicted prosocial fashion regardless of the strength of CSR situational norms. However, strong perceptions of organizational social responsibility can have a unique overriding function on employees' proactively responsible behaviors regardless of their responsibility orientation, making it difficult to tell the difference between the disposition-driven responsible individual and the employee who succumbs to situational norms. This underscores the importance organizations must place on ensuring that a positive CSR message is understood in a homogenous way across the organization, as the variance of perceptions observed in this study indicates a certain amount of "noise" between the organization's actions and employees' responses. Together, these findings emphasize the importance organizations must place on the design, implementation, and communication of CSR, and the utility of selecting for or encouraging proactive and socially responsible characteristics in employees. This study contributes to the literature on proactive helping, CSR, and responsibility more generally by revealing further interplay between prosocial dispositional behavioral tendencies and organizational prosocial actions. 


\section{AUTHOR CONTRIBUTIONS}

DER developed the original idea for this project, with DBM expanding the ideas and writing up the proposal and first draft. DBM, DER and NP designed the data collection procedure and survey. DBM and LT performed the data analyses. All authors contributed to revisions, which were led by DER.

\section{CONFLICTS OF INTEREST}

The authors declare that there are no conflicts of interest.

\section{ACKNOWLEDGEMENTS}

We are grateful to Dasol Kim, Siyoung Jung, Fizza Haider, Stephanie Rigdon, and Jessie Cannon for research assistance with this study.

\section{REFERENCES}

1. Aguilera RV, Rupp DE, Williams CA, Ganapathi J. Putting the S back in corporate social responsibility: A multilevel theory of social change in organizations. Acad Manag Rev. 2007;32(3):836-63.

2. Davis K. The case for and against business assumption of social responsibilities. Acad Manag J. 1973;16(2):312-22.

3. Glavas A. Corporate social responsibility and organizational psychology: An integrative review. Front Psychol. 2016;7(144):1-13.

4. Jones DA, Rupp DE. Social responsibility IN and OF organizations: The psychology of corporate social responsibility among organizational members. In: Ones DS, Anderson N, Viswesvaran C, Sinangil HK, editors. The handbook of industrial, work and organizational psychology. London (UK): Sage; 2018. p. 333-50.

5. McWilliams A, Rupp DE, Seigel DS, Stahl G, Waldman DA. New developments in the study of corporate social responsibility. In: McWilliams A, Rupp DE, Seigel DS, Stahl G, Waldman DA, editors. The oxford handbook of corporate social responsibility: psychological and organizational perspectives. Oxford (UK): Oxford University Press; 2019.

6. Willness C, Strah N, Rupp DE, Jones DA. Corporate social responsibility at the individual level of analysis: Research findings that inform responsible management "in the wild". In: Laasch O, Jamali OD, Freeman E, Suddaby R, editors. Research handbook of responsible management. Cheltenham (UK): Edward Elgar; 2020.

7. Rupp DE, Mallory DB. Corporate social responsibility: Psychological, personcentric, and progressing. Annu Rev Organ Psychol Organ Behav. 2015;2(1):211-36.

8. Crilly D, Schneider SC, Zollo M. Psychological antecedents to socially responsible behavior. Eur Manag Rev. 2008;5(3):175-90.

9. Ones DS, Dilchert S. Employee green behaviors. In: Jackson SE, Ones DS, Dilchert S, editors. Managing human resources for environmental sustainability. Hoboken (NJ, US): John Wiley \& Sons; 2012. p. 85-116. 
10. Gond J-P, El Akremi A, Swaen V, Babu N. The psychological microfoundations of corporate social responsibility: A person-centric systematic review. J Organ Behav. 2017;246(2):225-46.

11. Blok V, Wesselink R, Studynka O, Kemp R. Encouraging sustainability in the workplace: A survey on the proenvironmental behavior of university employees. J Clean Prod. 2015;106:55-67.

12. Lamm E, Tosti-Kharas J, King C. Empowering employee sustainability: Perceived organisational support toward the environment. J Bus Ethics. 2015;128:207-20.

13. Bateman TS, Crant JM. The proactive component of organizational behavior: A measure and correlates. J Organ Behav. 1993;14(2):103-18.

14. Fuller JB, Marler LE, Hester K. Promoting felt responsibility for constructive change and proactive behavior: Exploring aspects of an elaborated model of work design. J Organ Behav. 2006;27(8):1089-120.

15. Morrison EW, Phelps CC. Taking charge at work: Extrarole efforts to initiate workplace change. Acad Manag J. 1999;42(4):403-19.

16. Bandura A. A social cognitive theory of personality. In: Pervin L, John O, editors. Handbook of personality. 2nd ed. New York (NY, US): Guilford Publications; 1999. p. 154-96.

17. Li N, Liang J, Crant JM. The role of proactive personality in job satisfaction and organizational citizenship behavior: A relational perspective. J Appl Psychol. 2010;95(2):395-404.

18. Tett RP, Burnett DD. A personality trait-based interactionist model of job performance. J Appl Psychol. 2003;88(3):500-17.

19. Fuller JB, Marler LE. Change driven by nature: A meta-analytic review of the proactive personality literature. J Vocat Behav. 2009;75(3):329-45.

20. Parker SK, Williams HM, Turner N. Modeling the antecedents of proactive behavior at work. J Appl Psychol. 2006;91(3):636-52.

21. Weiss HM, Rupp DE. Envisioning a person-centric work psychology. Ind Organ Psychol. 2011;4(1):138-43.

22. Rank J, Pace VL, Frese M. Three avenues for future research on creativity, innovation, and initiative. Appl Psychol. 2004;53:518-28.

23. Bolino MC, Grant AM. The bright side of being prosocial at work, and the dark side, too: A review and agenda for research on other-oriented motives, behavior, and impact in organizations. Acad Manag Ann. 2016;10(1):599-670.

24. Smith CA, Organ DW, Near JP. Organizational citizenship behavior: Its nature and antecedents. J Appl Psychol. 1983;68(4):653-63.

25. Seibert SE, Kraimer ML, Crant JM. What do proactive people do? A longitudinal model linking proactive personality and career success. Pers Psychol. 2001;54(4):845-74.

26. Fay D, Sonnentag S. A look back to move ahead: New directions for research on proactive performance and other discretionary work behaviours. Appl Psychol. 2010;59(1):1-20.

27. Campbell DJ. The proactive employee: Managing workplace initiative. Acad Manag Perspect. 2000;14:52-66.

28. Parker SK, Collins CG. Taking stock: Integrating and differentiating multiple 
proactive behaviors. J Manage. 2010;36(3):633-62.

29. Altman BW, Vidaver-Cohen D. A framework for understanding corporate citizenship: Introduction to the special edition of Business and Society Review 'Corporate Citizenship for the New Millennium'. Bus Society Rev. 2000;105:1-7.

30. Sethi SP. Standards for corporate conduct in the international arena: Challenges and opportunities for multinational corporations. Bus Society Rev. 2002;107:20-40.

31. Tornau K, Frese M. Construct clean-up in proactivity research: A metaanalysis on the nomological net of work-related proactivity concepts and their incremental validities. Appl Psychol. 2013;62(1):44-96.

32. Berkowitz L. Responsibility, reciprocity, and social distance in help-giving: An experimental investigation of english social class differences. J Exp Soc Psychol. 1968;4(1):46-63.

33. Berkowitz L, Friedman P. Some social class differences in helping behavior. J Pers Soc Psychol. 1967;5(2):217-25.

34. Darley JM, Latané B. Bystander intervention in emergencies: Diffusion of responsibility. J Pers Soc Psychol. 1968;8(4, Pt.1):377-83.

35. Tilker HA. Socially responsible behavior as a function of observer responsibility and victim feedback. J Pers Soc Psychol. 1970;14(2):95-100.

36. Schwartz SH. Normative explanations of helping behavior: A critique, proposal, and empirical test. J Exp Soc Psychol. 1973;9(4):349-64.

37. Mayer FS, Duval S, Holtz R, Bowman C. Self-focus, helping request salience, felt responsibility, and helping behavior. Personal Soc Psychol Bull. 1985;11(2):133-44.

38. Goranson RE, Berkowitz L. Reciprocity and responsibility reactions to prior help. J Pers Soc Psychol. 1966;3:227-32.

39. Hackman JR, Oldham GR. Motivation through the design of work: Test of a theory. Org Behav Human Perf. 1976;16(2):250-79.

40. Frese M, Kring W, Soose A, Zempel J. Personal initiative at work: Differences between East and West Germany. Acad Manag J. 1996;39(1):37-63.

41. Cantor N. From thought to behavior: "Having" and "doing" in the study of personality and cognition. Am Psychol. 1990;45(6):735-50.

42. Dilchert S, Ones DS. Measuring and improving environmental sustainability. In: Jackson SE, Ones DS, Dilchert S, editors. Managing human resources for environmental sustainability. Hoboken (NJ, US): John Wiley \& Sons; 2012. p. 187-221.

43. Carroll AB. Corporate social responsibility: Evolution of a definitional construct. Bus Soc. 1999;38(3):268-95.

44. Valor C. Corporate social responsibility and corporate citizenship: Towards corporate accountability. Bus Society Rev. 2005;110(2):191-212.

45. Organ DW. Organizational citizenship behavior: The good soldier syndrome. Lexington, (MA, US): Lexington Books/D. C. Heath and Com; 1988.

46. Podsakoff NP, Whiting SW, Podsakoff PM, Blume BD. Individual- and organizational-level consequences of organizational citizenship behaviors: A meta-analysis. J Appl Psychol. 2009;94(1):122-41.

47. Pearce JL, Gregersen HB. Task interdependence and extrarole behavior: A test 
of the mediating effects of felt responsibility. J Appl Psychol. 1991;76(6):83844.

48. Choi JN. Change-oriented organizational citizenship behavior: Effects of work environment characteristics and intervening psychological processes. J Organ Behav. 2007;28(4):467-84.

49. Boiral O. Greening the corporation through organizational citizenship behaviors. J Bus Ethics. 2008;87:221-36.

50. Kaiser FG. A general measure of ecological behavior. J Appl Soc Psychol. 1998;28(5):395-422.

51. Sackett PR. The structure of counterproductive work behaviors: Dimensionality and relationships with facets of job performance. Int J Sel Assess. 2002;10(1\&2):5-11.

52. Graham JW. Principled organizational dissent: A theoretical essay. Res Org Behav. 1986;8:1-52.

53. Frese M, Fay D, Hilburger T, Leng K, Tag A. The concept of personal initiative: Operationalization, reliability and validity in two German samples. J Occup Organ Psychol. 1997;70(2):139-61.

54. Warren DE. Constructive and destructive deviance in organizations. Acad Manag Rev. 2003;28(4):622-32.

55. Morrison EW. Doing the job well: An Investigation of pro-social rule breaking. J Manag. 2006;32(1):5-28.

56. Sackett PR, Berry CM, Wiemann SA, Laczo RM. Citizenship and counterproductive behavior: Clarifying relations between the two domains. Human Perf. 2006;19(4):441-64.

57. Hoon H, Tan TML. Organizational citizenship behavior and social loafing: The role of personality motives, and contextual factors. J Psychol: Interdiscip Appl. 2008; 142(1):89-108.

58. Tett RP, Guterman HA. Situation trait relevance, trait expression, and crosssituational consistency: Testing a principle of trait activation. J Res Pers. 2000;34(4):397-423.

59. Mischel W. Toward a cognitive social learning reconceptualization of personality. Psychol Rev. 1973;80(4):252-83.

60. Meyer RD, Dalal RS, José IJ, Hermida R, Chen TR, Vega RP, et al. Measuring jobrelated situational strength and assessing its interactive effects with personality on voluntary work behavior. J Manage. 2014;40(4):1010-41.

61. Nye M, Hargreaves T. Exploring the social dynamics of proenvironmental behavior change. J Ind Ecol. 2010;14:137-49.

62. Mischel W, Shoda Y. A cognitive-affective system theory of personality: Reconceptualizing situations, dispositions, dynamics, and invariance in personality structure. Psychol Rev. 1995;102(2):246-68.

63. Dubois CLZ, Astakhova MN, DuBois DA. Motivating behavior change to support organizational environmental sustainability goals. In: Huffman $\mathrm{AH}$, Klein SR, editors. Green organizations: Driving change with I-O psychology. New York (NY, US): Routledge; 2013. p. 186-207.

64. Hayes AF. PROCESS: A versatile computational tool for observed variable mediation, moderation, and conditional process modeling [white paper]. 2012. Available from: http://www.afhayes.com/public/process2012.pdf. Accessed 
2019 Dec 1.

65. Preacher KJ, Rucker DD, Hayes AF. Addressing moderated mediation hypotheses: Theory, methods, and prescriptions. Multivar Behav Res. 2007;42(1):185-27.

66. Jones DA, Willness CR, Madey S. Why are job seekers attracted by corporate social performance? Experimental and field tests of three signal-based mechanisms. Acad Manag J. 2014;57(2):383-404.

67. Skarlicki DP, Folger R. Retaliation in the workplace: The roles of distributive, procedural, and interactional justice. J Appl Psychol. 1997;82(3):434-43.

68. Bandalos DL, Finney SJ. Item parceling issues in structural equation modeling. In: Marcoulides G, Schumacker R, Sterba SK, MacCallum RC, editors. New developments and techniques in structural equation modeling. Mahwah (NJ, US): Lawrence Erlbaum Associates, Inc; 2001. p. 1-354.

69. Sterba SK, MacCallum RC. Variability in parameter estimates and model fit across repeated allocations of items to parcels. Multivar Behav Res. 2010;45(2):322-58.

70. Kline R. Principles and practice of structural equation modeling. 2nd ed. New York (NY, US): Guilford Publications; 2005.

71. Nunnaly JC, Bernstein IH. Psychometric theory. 3rd ed. New York (NY, US): McGraw-Hill; 1994. Vol. 3.

72. Belsley D, Kuh E, Welsch R. Detecting and assessing collinearity. In: Regression diagnostics: Identifying influential data and sources of collinearity. Hoboken (NJ, US): John Wiley \& Sons; 1980. p. 85-91.

73. Aiken LS, West SG. Multiple regression: Testing and interpreting interactions. Newbury Park (CA, US): Sage; 1991.

74. Edwards JR, Lambert LS. Methods for integrating moderation and mediation: A general analytical framework using moderated path analysis. Psychol Methods. 2007;12(1):1-22.

75. Guo J, Rupp DE, Weiss HM, Trougakos JP. Justice in organizations: A personcentric perspective. In: Gilliland SW, Steiner DD, Skarlicki DP, editors. Emerging perspectives on organizational justice and ethics. Greenwich (CT, US): Information Age; 2011. p. 3-32.

76. Bhattacharya CB, Sen S, Korschun D. Using corporate social responsibility to win the war for talent. MIT Sloan Manag Rev. 2008;49:37-44.

77. Mallory DB, Rupp DE. “Good” leadership: Using corporate social responsibility to enhance leader-member exchange. In: Bauer TN, Erdogan B, editors. The oxford handbook of leader member exchange: 1-20. Oxford (UK): Oxford University Press; 2014.

78. McShane L, Cunningham PH. To thine own self be true? Employees' judgments of the authenticity of their organization's corporate social responsibility program. J Bus Ethics. 2012;108(1):81-100.

79. Rupp DE, Shao R, Thornton MA, Skarlicki DP. Applicants' and employees' reactions to corporate social responsibility: The moderating effects of firstparty justice perceptions and moral identity. Pers Psychol. 2013;66(4):895-933.

80. Murphy KR. Honesty in the workplace. Pacific Grove, (CA, US): Brooks/Cole; 1993.

81. LeBlanc MM, Kelloway EK. Predictors and outcomes of workplace violence 
and aggression. J Appl Psychol. 2002;87(3):444-53.

82. O’Leary-Kelly AM, Griffin RW, Glew DJ. Organization-motivated aggression: A research framework. Acad Manag Rev. 1996;21(1):225-53.

83. Schmitt N. Method bias: The importance of theory and measurement. J Organ Behav. 1994;15(5):393-8.

84. Pratt MG. Identities in organizations: Building theory through conversations. Whetten DA, Godfrey PC, editors. Thousand Oaks (CA, US): SAGE Publications, Inc.; 1998.

85. Van Dyne L, Vandewalle D, Kostova T, Latham ME, Cummings LL. Collectivism, propensity to trust and self-esteem as predictors of organizational citizenship in a non-work setting. J Organ Behav. 2000;21(1):3-23.

86. Williams S, Shiaw W. Mood and organizational citizenship behavior: The effects of positive affect on employee organizational citizenship behavior intentions. J Psychol. 1999;133(6):656-68.

87. Spector PE. Method variance in organizational research: Truth or urban legend? Organ Res Methods. 2006;9(2):221-32.

88. Chung J, Monroe GS. Exploring social desirability bias. J Bus Ethics. 2003;44(4):291-302.

89. Spector PE, Fox S, Penney LM, Bruursema K, Goh A, Kessler S. The dimensionality of counterproductivity: Are all counterproductive behaviors created equal? J Vocat Behav. 2006;68(3):446-60.

How to cite this article:

Mallory DB, Rupp DE, Pandey N, Tay L. The Effect of Employee Proactive Personality and Felt Responsibility on Individual Corporate Social Responsibility Behaviors: The CSR Context Matters. J Sustain Res. 2021;3(1):e210002. https://doi.org/10.20900/jsr20210002 